\title{
The Distribution Strategies of Convenience Stores Chain in China from Japan 7-11
}

\author{
Ting Huang ${ }^{1}$ and Chunxiong Liu ${ }^{1}$ \\ ${ }^{1}$ Department of Management ang Engineering, Zhengzhou University, Zhengzhou 450001, China
}

\begin{abstract}
With the rapid development of China's supermarket chain industry, logistics distribution technology has become more and more important. Regarded as the core technology of chain operation, it is the basis of success in chain operation. At present, logistics distribution system's backward has hindered the development of China's chain enterprises. Based on the success of Japan 7-11, this paper makes a research on centralized shop strategy, diversified information management and the high efficiency of logistics distribution strategy, and seeks to optimize profits of logistics distribution from the perspective of enterprise strategy. Besides, this paper analyses the advantages and disadvantages of the mode of chain enterprises and gives advice on promoting chain enterprises.
\end{abstract}

Keywords. Logistics distribution, chain operation, logistics cost.

\section{Introduction}

As an important form of enterprise organization, chain enterprises play an important role in the development of China's economy. The rise of chain operation is in China's coastal city in the last century 80s and $90 \mathrm{~s}$. After 20 years' development, chain operation has made great progress and has developed into a retail business model in the world with great vitality and development prospects. However, there are still a series of problems compared with other countries in the world. For example, it does not have a high level in convenience store chain, and its scale is limited. Besides its business characteristics are not clear, and market positioning and supermarket have in common. The lack of features and service merchandise is also a problem. Logistics distribution lags behind and development in different areas is unbalanced. Japan 7-Eleven convenience store chain, as the world's largest chain enterprises, its experience in the logistics distribution of chain enterprises worth learning for China. Japan 7-11 convenience store chain has obtained great achievement today, it cannot do without the effective operation of the brand, unique management style, and market strategy based on region, comprehensive management information system, diversified logistics distribution are the key to success.

\section{The overview of Japan 7-11 convenience store chain}

7-11 brand was of the South Company of America, and became a Japanese company in 2005. Founded in 1927 in Texas, the name of the 7-11 came from the year of 1946, and its business hour was from 7 am to $11 \mathrm{pm}$. Then it was introduced by the Japanese retail manager Ito Yokado to Japan in 1974, and changed to 24 hours a day of business from the beginning of 1975. Until now, its shops are permeated with China, the United States, Japan, Singapore, Malaysia, Philippines, Thailand and other countries and regions [1].

Japan 7-11 convenience store's business area is basically in about 100 square meters. Its varieties are about 3000 varieties and they are all popular goods. Among them, food accounts for about $75 \%$, magazines, daily necessities is about $25 \%$. The headquarter recommends 80 new varieties monthly to its franchisee, so that the variety of merchandise business is often replaced to adapt to market changes as well as gives customers a sense of freshness. The convenience store business not only satisfy daily necessities, but also can help the region take charge of electricity rates, gas rates, water rates, fast broadcast rates, postage rates and so on. It is a real convenience store which attends to people.

\section{The analysis of Japan 7-11 convenience store distribution strategy}

Japan 7-11's success is mainly due to the design and management of its supply chain.Japan 7-11's business purpose is to provide them with products when the customers need. From a strategic point of view, one of the main objectives of the company is to seek the micro balance between supply and demand through the regional, seasonal and daily schedule. Then this paper will analyses the 7-11 convenience store distribution strategy. 


\subsection{Market strategy closed to the region}

One of the main location strategy of 7-11 company is to follow a high density centralized stores, and enter a any new market. It is about to establish 50-60 intensive shops supported by the distribution center [2].

7-11 convenience store distribution system develops from a single wholesaler stage to the intensive development of the distribution system, then to common distribution system. It delivered by the manufacturer to the distribution center, and the distribution center through the milk run route to store delivery. Common distribution system saves transportation costs and reduce the cost of the store to receive goods. The shop can save less inventory through frequent replenishment.

Therefore, the implementation of the distribution strategy can get the following results.

\subsubsection{Saving advertising costs for each store}

The main advertising media of $7-11$ is the television advertisement. If we consider the radiation range of every convenience store as a small area, when the area has many convenience stores who need for publicity through television advertising, which can also achieve the same effect by television advertisement. The advertising cost of one store or a few stores are the same, but to every store is different. Therefore, the more stores there is, the less advertising costs each store has.

\subsubsection{Conducive to improve the efficiency of the 7-11 chain of the department of service}

Japan 7-11 convenience store chain has the position of manager, that is OFC (Fiber Contr01 Open). Each area manager who is responsible for guiding the number of stores is about 7 or 8 . This figure, based on the work of the area manager, has not changed from the past to the present. It is estimated that the future will not change. Now, we assume a situation, if the number of stores in the area is reduced and scattered, so the time cost for the administrator in the guidance process is relatively high, and then to the store instruction frequency will be reduced, and the time to the store guidance and communication will be reduced, which will reduce the quality of guide service. When stores are concentrated, the time cost for the manager to every district is relatively small, then the effect will be good. It will increase guidance frequency for the store to enhance the quality of guidance.

\subsubsection{Brand aggregation effect}

We can imagine, walking in the streets of Japan, we will be able to see a 7-11 convenience store signs every distance, which will produce a kind of visual perception [3]. The more signs we see, the more favorable to the company's popularity to improve, which will attain the effect of brand image multiplication. At the same time, it can also avoid a temporary closure of the accident or temporary shortage caused by the lack of sales opportunities, and to affect customer satisfaction or company reputation.

\subsection{The implementation of a comprehensive Information system management strategy}

7-11 convenience store has developed a comprehensive information system. It can be said that the success of the 7-11 benefits mostly to its comprehensive information system. This system is installed in each stores of 7-11, so you can keep in touch with the headquarter, suppliers and 7-11 distribution centers. The system is processing the day's sales data before 11 o'clock every night, so that the second day's morning will be the analysis of the business data.

The use of information systems of 7-11 can better maintain the balance of supply and demand of the store. Stores can adjust the goods on the shelves based on a day's consumption patterns. Information is delivered directly to the supplier and distribution center when the store orders. The supplier received the order to start the stock to complete the production. There is no necessary for people at the scene when the 7-11 store deliver goods. Using scanning equipment to collect goods, so the entire system is based on trust.

The using of multimedia to carry out the distribution of goods is also a major feature of 7-11. Through the satellite communication system, we can send multimedia advertising, weather forecast and cloud charts, and even electronic products to the store. In this way, we can achieve the multimedia information, product sales and distribution of multimedia. In the 7-11 weather forecast, it actively explores the sales of food and weather correlation. The information system will collect weather reports five times every day, so that the local store can get a reference. Based on the weather forecast, the convenience store can master the weather conditions in advance. According to the weather conditions, we can select the number of distribution of goods and optimize the distribution route. The information system also collects the age information of customers to better grasp the customers' demand. Data is generally evaluated by the company, the area, and the store. 
Logistics distribution is the last link between producers and consumers in the circulation of goods. The speed of logistics and distribution efficiency directly affect the degree of customer satisfaction. The important reason for the rapid development of 7-11 is that there is a strong rear logistics support system. In addition, its logistics system can match the common distribution model. Regional centralized shop strategy for the use of common distribution model, that is, the establishment of joint distribution centers in each region to achieve high frequency, varieties, and small unit distribution effect. Acted as a common distribution center fully reflect the sales of goods in transition and inventory information. The reducing of transportation costs, 7-11 gradually grasps the dominant power of the whole industry chain.

There are two main characteristics of 7-11 in the logistics management.

\subsubsection{Implementing the aggregated distribution, and establishing a joint distribution center}

Summary distribution is a unique distribution system of 7-11 company. Japan 7-11 company's circulation is implemented by the manufacturer designated wholesalers purchase of the special wholesale system. The same product has different manufacturers, so special wholesalers are also different. So, if we want to complete many manufacturers of goods here, it requires the distribution channels and distribution of different delivery vehicles, and then increase the delivery vehicles. In order to solve this problem, 7-11 company adopted a summary distribution method. The distribution area of a commodity which was responsible by various wholesalers in the past is distributed to each wholesaler. A wholesaler is responsible for all stores and distribution area, thus increasing the number of distribution to each store, reducing the number of receiving stores, and raising the efficiency of transportation. Owing to the narrow distribution area, it also can shorten the delivery distance and time distribution.

\subsubsection{Quick response to customer needs}

In Japan 7 - Eleven chain convenience stores, when the customers went to the cashier checkout, the cashiers will scan the bar code firstly, and offer the customers a quote. After paying, the cashier will firstly input the amount paid by the customers. Then according to their estimate of age and gender, they press buttons above the POS which blue is for men and pink is for women. There are numbers 12, 19, 29, 39, 50 according to the corresponding digital open POS cash register and change. After checkout the data is passed through the network to the headquarters of the mainframe computers. So OFC and store headquarters can get instant updated data information and data analysis of customers' demand. Through the analysis of the data, OFC can grasp the trend of every hour and every customer's demand, and the price and inventory of every customer. Through the integration of these areas, products and time data, the speed of the headquarters mastering the customer demand is greatly improved. It can help to forecast the sales trend timely every day, to adjust the price, tally and distribution activities.

\section{The distribution of chain supermarket enterprises in our country}

The chain supermarket in our country has become the most dynamic industry in the commercial field. Over the past few years, large and medium-sized chain supermarket sales volume increased year by year. Sales growth was significantly higher than the total retail sales of social commodities and the growth of traditional department stores [4].

Despite the development of China's supermarket chain, in general, China's supermarket chain is still in the primary stage. Whether from its share of the total retail sales of social goods, or from its development stage and management level, there are still a lot of mistakes and the lack of management level .

\subsection{High distribution costs}

In order to achieve high profit and high service level, it is necessary to reduce the distribution cost and increase the profit of the enterprise. Therefore, the company need to consider from the aspects of the purchase, the distribution of vehicles, the design of distribution routes, and so on.

\subsection{The low degree of information}

The application of computer information technology is not high in Logistics distribution center, and many important decisions have been done still in a state of artificial. The problems which were found in the distribution process and feedback are not timely, which leads that he treatment is not timely, and the efficiency of the work is reduced. In addition, the application of the computers is limited to the management of daily affairs. Most of the centers have not been fully established, which affects not only the quality of the distribution but also the speed of distribution.

\subsection{Low service level}


The function is not completed, which further leads to the backwardness of the service level. Distribution is the organic combination of "distribution" and "delivery". It is a modern logistics activity, and it also emphasizes the function of coordination and integration. But from the current situation of chain supermarket distribution in our country, there are still a lot of problems. On the one hand, although some distributions do inventory, goods, distribution, but it can only achieve the function of storage, and can not be door-to-door due to the lack of necessary transport vehicles, resulting in the seperation between "coordination" and "send". On the other hand, most of the goods are just to be sent, rarely considering the distribution, distribution processing and other functions.

Based on the above three points, we can draw a conclusion that if China's local supermarket chain enterprises want to keep their own position, the reform is urgent to achieve the expansion of the scale and market share of the upgrade.

\section{Japan 7 - eleven chain convenience store distribution strategy can be used for reference in china's chain supermarket}

As the world's largest chain enterprise, 7-Eleven can be said to achieve a big success today. In addition to the effective use of the brand, the agglomeration effect, as well as its unique way of management, it mainly lies in the effective logistics strategy, and this point is just the "bottleneck" in Chinese supermarket chain industry development. We can learn from the distribution strategy of 7-Eleven in the success of some successful experiences, combining with the characteristics of China's chain enterprises, so that we can establish a chain of retail mode in line with the development of China's national conditions [5].

After comprehensive analysis, we can improve from the following aspects.

\subsection{Improving the efficiency of logistics distribution of chain enterprises in our country}

From the successful experience of Japan 7- Eleven convenience store, the high efficiency of logistics and distribution, the building of joint distribution center and the rapid response of customer demands are the key to its success. Starting with the details, for example, the analysis of consumer data, optimal design of logistics distribution route, we need to set the improvement of the distribution efficiency as the top priority of the work.

\subsection{Improving the construction and management level of the chain enterprise's information system in our country}

The degree of information is not high and most of them are artificial, which is a common problem of many enterprises in our country. It seriously affected the rapid and healthy development of enterprises. Japan 7-Eleven company has made good use of advanced information technology, and established a comprehensive enterprise internal multi-faceted information management system to achieve the information sharing between the stores. If the chain enterprises in our country want to get rid of the shackles of the existing development, we should change the idea firstly, fully utilize advanced technology to establish a complete information system, and strengthen the monitoring, analysis and improvement of each links. At the same time, like the 7-Eleven, we ought to put the climate change, the changes in the market environment, the age of the customer base, customer's purchase preferences and other factors into the system to achieve stable old customers and constantly open up new customers.

\subsection{Changing the existing business strategy to improve service level}

Retail convenience stores are different from ordinary supermarkets. Convenience stores have longer service time as well as a small store, which are closer to life. But looking at the development of chain enterprises in our country, influenced by Chinese traditional concepts, the development still can not get rid of the family style business model and ideas. At the same time, the phenomenon of high cost of distribution, lack of funds and lack of core competitiveness still exist. Japan 7-Eleven convenience stores take a series of effective measures to reduce the cost, open stores and improve market share and distribution efficiency. Therefore the chain enterprises in our country should change the business strategy, pay attention to the purchasing ability, brand effect, traffic condition and the improvement of the logistics cost.

\subsection{Improving the quality control of the distribution of goods}

7-11 convenience is famous for operating a wide variety of goods, and the following chart gives the proportion of its sales of goods.

Table 1. The proportion of 7-Eleven store sales of different types of goods.

\begin{tabular}{|c|c|}
\hline $\begin{array}{c}\text { Type of } \\
\text { commodity sales }\end{array}$ & Percentage (\%) \\
\hline
\end{tabular}




\begin{tabular}{|c|c|}
\hline $\begin{array}{c}\text { Processed foods } \\
\text { (snacks, beverages) }\end{array}$ & 31.64 \\
\hline $\begin{array}{c}\text { Snack foods (rice, } \\
\text { lettuce, fried food, } \\
\text { etc.) }\end{array}$ & 30.25 \\
\hline $\begin{array}{c}\text { Day sales of food } \\
\text { (milk, yogurt, etc.) }\end{array}$ & 12.75 \\
\hline $\begin{array}{c}\text { Non food } \\
\text { (magazine, daily } \\
\text { necessities, game } \\
\text { software, etc.) }\end{array}$ & 25.36 \\
\hline Total & 100 \\
\hline
\end{tabular}

Data from the above chart can be seen that 7-Eleven convenience stores operate a wide variety of goods. Enterprises implement the logistics and distribution management in accordance with the different characteristics of different products, and thus ensure the freshness of products. The new management method is to establish distribution system according to different temperatures. 7-Eleven's temperature management of goods is mainly divided into four forms, as shown in Table 2 below.

Table 2. Types of temperature management of goods.

\begin{tabular}{|c|c|}
\hline $\begin{array}{c}\text { Type of } \\
\text { temperature } \\
\text { management }\end{array}$ & $\begin{array}{c}\text { The main application of } \\
\text { goods }\end{array}$ \\
\hline $\begin{array}{c}\text { Freezing type }(20 \\
\text { degrees below } \\
\text { zero) }\end{array}$ & $\begin{array}{c}\text { Normal } \\
\text { Initials followed by last name }\end{array}$ \\
\hline $\begin{array}{c}\text { Micro cold type } \\
\text { (5 degree) }\end{array}$ & $\begin{array}{c}\text { Normal } \\
\text { Abbreviated }\end{array}$ \\
\hline $\begin{array}{c}\text { Normal } \\
\text { temperature type }\end{array}$ & Italic \\
\hline $\begin{array}{c}\text { Warm type }(20 \\
\text { degrees })\end{array}$ & Bold \\
\hline
\end{tabular}

Different products have different temperature managements according to the characteristics, then it can meet the customers' requirements of product freshness and commodity quality. For local chain enterprises in our country, being strict with quality and temperature division to ensure product freshness and taste, then we can seize market share in the fierce market competition to win the magic weapon.

The Japan 7-Eleven convenience store chain becomes the world's largest chain enterprise due to its effective logistics strategy, comprehensive information system management strategy and efficient logistics distribution mode. According to the characteristics of the development of local chain enterprises in our country, we should draw the effective operation and distribution strategy of 7-Eleven convenience store. We can make some improvement from the distribution cost, service level, information construction and other aspects and we will be able to build a successful chain of supermarket industry with Chinese characteristics.

\section{References}

1. Baidu Encyclopedia.7-11 convenience store. Search engine.

2. Du Haiqing. Close to the region: Japanese 7-11 market. Value of China, (03/19/2006).

3. Cheng Yanfei. Japan 7-11 convenience store market expansion strategy of. information and computer, 64-65 (2010).

4. Xiao Chun, Wen Jinjun. The development of retail industry in China under the joint distribution mode - Japan 7-11 convenience store logistics innovation inspiration. Logistics technology, volume twenty-ninth, 29(11), 27-29 (2006).

5. Liu Jianmin.7-11 convenience store logistics operation of China's Chinese fast food logistics enlightenment. Guangdong Logistics technology, 25-27 (2008). 